\title{
TRAJETÓRIAS E FUNÇÕES DE CIDADES MÉDIAS NA ARGENTINA. \\ Algunas reflexões e evidências
}

\section{TRAYECTORIAS Y FUNCIONES DE CIUDADES INTERMEDIAS EN ARGENTINA.}

\author{
Algunas reflexiones y evidencias
}

\begin{abstract}
Silvia Gorenstein
Economista. CONICET-Departamento de Economía- Universidad Nacional del Sur-Argentina. sgoren@criba.edu.ar

Graciela Landriscini

Economista Departamento de Economía-Universidad Nacional del Comahue-Argentina. gslandriscini@speedy.com.ar;

Martín Napal

Economista (Maestrando Departamento de Economía-Universidad Nacional del Sur-Argentina. mjnapal@yahoo.com.ar
\end{abstract}

\begin{abstract}
RESUMO
Este artigo apresenta algumas evidências e reflexões desenvolvidas no âmbito do estudo realizado em três cidades do território argentin (Bahía Blanca, Río Cuarto, Neuquén), que compartilham a característica de uma dinâmica sócio-econômicas fortemente associado com complexo de produção baseada em recursos naturais. Esta abordagem permitiu compreender o papel dessas cidades, dois e um pampas e um da Patagônia, com as suas funções específicas e as áreas de prestação de serviços, tradicionais e avançadas, e como locais de impacto diferenciado do atual ciclo econômico dos setores ligados à produção de matérias-primas e alimentos.

Nós perguntou em artigo sobre o tipo de intermediação exercício atraente para as cidades estudadas três exios de análise. $\mathrm{O}$ primeiro relaciona-se com a funcionalidade dessas cidades, as mudanças que ocorreram ao longo de seu trajetória, e os fatores que motorizados. O segundo concentra-se na composição da estrutura económica urbana, proporcionando elementos de análise e discussão das dinâmicas que impressão atividades intensivas em recursos naturais como uma fonte de demanda por bens, serviços e mão de obra. O terceiro incide sobre o sistema local de inovação como motor de mudança na função de intermediação urbana, para além da sua articulação ou não destas atividades, com especialização regional.

As conclusões e reflexões incentivar aida mais estudos comparativos com outras cidades e regiões do país e do continente.
\end{abstract}

Geo UERJ - Ano 15, nº 24, v. 1, $1^{\circ}$ semestre de 2013 p. 339-370

ISSN: 1415-7543 E-ISSN: 1981-9021

http://www.e-publicacoes.uerj.br/index.php/geouerj 


\title{
Intermediários cidades-novas funções- centralidade-terciário-trajetórias urbanas
}

\begin{abstract}
RESUMEN
El presente artículo expone algunas evidencias y reflexiones elaboradas en el marco del estudio realizado en tres ciudades del territorio argentino (Bahía Blanca, Río Cuarto y Neuquén), que comparten la particularidad de una dinámica socio-económica fuertemente asociada a complejos productivos basados en recursos naturales. Este abordaje, ha permitido comprender el rol de estas ciudades, dos pampeanas y una norpatagónica, con sus funciones específicas como ámbitos de provisión de servicios, tradicionales y avanzados, y como sitios de repercusión diferenciada del actual ciclo económico expansivo de los sectores ligados a la producción de materias primas y alimentos.

Se ha indagado acerca del tipo de intermediación que ejercen las ciudades estudiadas apelando a tres ejes de análisis. El primero de ellos refiere a la funcionalidad de estos núcleos urbanos, los cambios que se han producido a lo largo de su trayectoria, y los factores que los motorizaron. El segundo eje gira en torno a la composición de la estructura económica urbana, proporcionando elementos de análisis y discusión sobre la dinámica que imprimen las actividades intensivas en recursos naturales como fuente de demanda de los mercados de bienes, servicios y de trabajo. El tercero focaliza en el sistema local de innovación como motor del cambio en la función de intermediación urbana, además de su articulación o no con dichas actividades de especialización regional.
\end{abstract}

Las conclusiones y reflexiones estimulan a profundizar los estudios comparativos con otras ciudades y regiones del país y el continente.

\section{Ciudades intermedias-nuevas funciones-centralidad-terciarización-trayectorias urbanas}

\section{Introducción}

El presente artículo expone avances del conocimiento generado a partir de una investigación desarrollada en red entre equipos de trabajo de distintas universidades argentinas ${ }^{1}$, en el que se planteó como objetivo el estudio de un conjunto de ciudades medias del territorio nacional, vista la importancia teórica y política que las mismas han adquirido en la globalización.

Reinterpretar lo urbano no metropolitano constituye un desafío analítico, para la orientación de políticas y para el diseño de mecanismos de gestión, en tanto las ciudades medias se han convertido en objeto de atención particular, a partir de reconocer las situaciones territoriales diferenciales, resultantes de factores estructurales, y las renovadas cuestiones que surgen en el funcionamiento económico de los sistemas urbano-regionales y sus estructuras productivas al ser impactadas por las dinámicas globalizadoras. En América Latina, estudios de estas características se llevan adelante en diversos países, motivados en los problemas derivados de

Geo UERJ - Ano 15, nº. 24, v. 1, $1^{\circ}$ semestre de 2013 p. 339-370

ISSN: 1415-7543 E-ISSN: 1981-9021

http://www.e-publicacoes.uerj.br/index.php/geouerj 
los tradicionales desequilibrios en los sistemas urbanos, y la necesidad de fortalecer la escala regional y local -de modo articulado a la instancia nacional- en los procesos de desarrollo, toda vez que el Estado intenta recuperar su rol protagónico en la planificación estratégica, la regulación de los mercados, las relaciones económicas internacionales, la actividad económica y el desenvolvimiento social.

En el proyecto se abordan los procesos asociados a las diferentes dinámicas socioeconómicas y espaciales donde se combinan la dimensión urbana y regional tales como: la de los complejos productivos regionalizados integrados en diferentes redes (global, nacional); la de la tercerización de las bases económicas; la de las trayectorias urbanas, centradas en las actividades e instituciones más relevantes; la de los mercados urbanos y rurales de trabajo; la de la ruralidad; y, en un sentido general, las modalidades que estos procesos asumen en escenarios periféricos de Argentina.

En su primera fase, el estudio se ha focalizado en centros pampeanos y nor patagónicos, cuya dinámica está fuertemente asociada a complejos productivos basados en recursos naturales, y se ha partido de los siguientes interrogantes:

$>$ Las ciudades medias analizadas, continúan actuando como centros articuladores regionales? Han incorporado nuevas funciones específicas? Cómo se ligan ellas al desenvolvimiento de los sectores productivos y de servicios?

$>$ Cómo han evolucionado las relaciones con otros centros urbanos y qué importancia alcanzan estas ciudades en la actual configuración del sistema urbano nacional?

> Cuáles son las áreas más dinámicas de estas economías urbanas? ¿Existen procesos de fortalecimiento y/o redefinición competitiva? Dónde están y cuál es la naturaleza de los centros de decisión de los procesos localizados?

$>$ Cuáles son las funciones avanzadas que se pueden identificar en las ciudades estudiadas? Qué relación tienen dichas funciones con los complejos productivos regionales? Son las que "sostienen" y/o "redefinen" la centralidad económica de las tres ciudades? En qué medida y a partir de qué actores?

Este abordaje, ha permitido comprender el rol de estas ciudades con sus funciones específicas como ámbitos de provisión de servicios, tradicionales y avanzados, como sitios de repercusión diferenciada del actual ciclo económico expansivo de los sectores ligados a la producción de materias primas y alimentos. Los tres centros reflejan el avance y modernización de las funciones de servicios, expresado ello en nuevos equipamientos, nuevas formas de producción, circulación y gestión y la expansión generalizada del terciario urbano, al tiempo que se Geo UERJ - Ano 15 , n ${ }^{\circ} .24$, v. $1,1^{\circ}$ semestre de 2013 p. 339-370 ISSN: 1415-7543 E-ISSN: 1981-9021 http://www.e-publicacoes.uerj.br/index.php/geouerj 
profundiza la articulación funcional y físico-territorial con sus entornos regionales. Junto a ello se detectan procesos migratorios, de segmentación laboral y fragmentación socioterritorial, los que se traducen en crecientes problemas en la apropiación y uso del suelo urbano, en la dotación de infraestructura y en otras cuestiones ambientales, los que por su alcance, gravitación y especificidad, se abordarán en otras fases de la investigación.

Ahora bien, cuando se explora la dinámica de las funciones urbanas desde la perspectiva de la estructura productiva regionalizada -actividades de especialización regional-, se visualizan redefiniciones que hacen al alcance y contenido de las relaciones urbano-regionales: por un lado se refuerzan y multiplican las conexiones espaciales signadas por la contigüidad y el dominio de estas ciudades, y por otro, emergen y se consolidan relaciones de superposición y articulación con otras escalas espaciales no definidas por la contigüidad, resultantes sobre todo de la configuración y dinámica en las cadenas productivas globales. Las tecnologías de información y comunicación juegan un papel relevante, activando el desarrollo de redes, si bien puede detectarse un balance dispar en términos de componentes, mecanismos y factores ligados a la llamada economía del conocimiento. Inciden en ello fuertemente, la imperfección de los mercados de nuevas tecnologías, los problemas de escala, el perfil de la demanda, y la relativa debilidad institucional de los sistemas locales de innovación.

En este sentido, las evidencias recogidas en la investigación muestran la importancia del principio del path-dependency en la especialización sectorial (petroquímica, gas y petróleo, y agroalimentario) con incipientes muestras de nuevas capacidades vinculadas a los activos y estrategias, principalmente públicas, ligados al desarrollo de sectores intensivos en conocimiento. Desde ambas perspectivas, se pueden observar fenómenos novedosos en términos del impacto en las ciudades, sus capacidades de adaptación y sus posibilidades de desarrollo, los que de todos modos aparecen como limitados en su alcance, y en los que gravitan la génesis y los caracteres institucionales y la configuración de las tramas productivas.

Entre las contribuciones conceptuales y empíricas que se desprenden de este abordaje, dos aspectos resultan relevantes para orientar la reflexión sobre las ciudades intermedias en el país:

En primer lugar, la importancia de sus trayectorias económicas y rasgos estructurales. Ello puede traducirse en circuitos que densifican, permean o destruyen entramados productivos, círculos virtuosos de relaciones económicas y tecnológicas y, en definitiva, contextos donde se definen capacidades de diversificación relacionada o no relacionada con la especialización urbano-regional.

Geo UERJ - Ano 15, no. 24, v. 1, $1^{\circ}$ semestre de 2013 p. 339-370

ISSN: 1415-7543 E-ISSN: 1981-9021

http://www.e-publicacoes.uerj.br/index.php/geouerj 
$>$ En segundo lugar, la masa crítica acumulada en los sectores ligados al conocimiento, y su integración o no a la base económica urbano regional. En tal sentido, la composición de la estructura ocupacional, su dinámica y los movimientos poblacionales, así como los niveles educativos de la población activa, son indicadores que -de algún modo- traducen diversidad entre ciudades.

\section{Revisando la cuestión teórica: la centralidad urbana y la ciudad intermedia}

\section{Intermediación y estructuración del territorio}

Al presente, las ciudades se han convertido en los nodos del espacio de flujos y en sitios estratégicos para los diversos circuitos globales, en el marco de la nueva geografía económica global, compuesta por regiones urbanas conectadas por complejas redes de interacción. "La funcionalidad urbana constituye así la razón de ser una ciudad, la causa explicativa de su dinamismo y la determinante de su escala territorial" (Precedo Ledo, 2002:24). Más allá del tamaño poblacional, son precisamente las funciones, su relevancia y diversidad, las que definen la centralidad urbana.

En su rol estructurante y organizador del territorio, las ciudades constituyen "el lugar a partir del cual se establece un control territorial" (Camagni, 2005:9), diferenciándose en términos de las funciones que desempeñan y la influencia que ejercen en su entorno inmediato y lejano. En otras palabras, la centralidad urbana es, en cierta forma, una medida de la jerarquía de la ciudad con relación a las funciones que desempeña y, consecuentemente, la "fuerza" que ejerce en la estructuración del espacio, en sus vinculaciones con la región y con el resto del territorio en las diferentes escalas geográficas.

La reorganización del sistema productivo en las últimas décadas, facilitada por el desarrollo y la difusión de las tecnologías de información y comunicación, originó un cambio en el funcionamiento del territorio: de un modelo jerárquico evolucionó a un modelo de organización más flexible y variable en forma de red. En este contexto, las ciudades de tamaño medio no solo actúan como nexo entre los niveles urbanos superiores e inferiores de la jerarquía urbana, sino que se vinculan con otras ciudades/territorios del mismo nivel jerárquico, que desarrollan funciones complementarias o similares en el espacio nacional e internacional, articulándose en diferentes redes (Marques da Costa, 2002:116; Usach y Garrido Yserte, 2009) y, como en el pasado, este tipo de centros recuperan su protagonismo en los procesos de desarrollo y ordenamiento territorial $^{2}$.

Geo UERJ - Ano 15, nº. 24, v. 1, $1^{\circ}$ semestre de 2013 p. 339-370

ISSN: 1415-7543 E-ISSN: 1981-9021

http://www.e-publicacoes.uerj.br/index.php/geouerj 
En el marco de un importante dinamismo demográfico ${ }^{3}$ y funcional, la creciente urbanización, y en el contexto de la descentralización espacial del capital productivo y/o terciario, estos centros urbanos se presentan como espacios privilegiados para atender las necesidades de reproducción del capital a partir de determinados atributos genéricos (Olivera, 2008): i) estar ubicadas en puntos estratégicos de la red urbana, ii) poseer importantes condiciones en materia de redes de transporte y comunicación, iii) ejercer una centralidad en nivel interurbano sobre determinada contigüidad territorial, y, iv) detentar las ventajas derivadas de la urbanización, sin sufrir las consecuencias negativas de las grandes dimensiones. ${ }^{4}$

Desde otra perspectiva, Pulido (2004) entiende que estas ciudades representan puntos de apertura hacia la internacionalización de los territorios de los cuales son motores, que tienen capacidad para producir y gerenciar sus propios recursos financieros, y desarrollar ciertas actividades claves para el movimiento global de concentración urbana. Dicho de otra forma, la posibilidad que tienen las ciudades intermedias de insertarse en las redes globales depende, de su posición geográfica y conexión a las grandes redes y flujos, de las estrategias de especialización competitiva y de complementariedad, del aprovechamiento de los recursos endógenos, de la capacidad creativa del medio y de adopción de innovaciones, y de la gestión institucional local-territorial del medio y sus recursos, así como del contexto regional, la "densidad económica" del territorio y el tipo de posicionamiento y el nivel de desarrollo económico de cada país (Llop Torné, 1999 y Fernandes et al., 2009).

\section{Las funciones de la ciudad intermedia}

Las funciones de intermediación que desarrollan estos centros urbanos (en relación a la región, la nación y el mundo) constituyen uno de los puntos centrales del debate teórico contemporáneo. En el nuevo contexto económico mundial, el desempeño de una ciudad intermedia -y las diferencias entre ellas- está estrechamente vinculado con su rol en la integración de flujos (personas, empresas, mercancías, etc.) de diferentes escalas espaciales (Hildreth, 2006). En tal sentido, interesa discutir dos cuestiones a partir del análisis de las funciones:

En primer lugar, la idea de que las ciudades se caracterizan por alguna funcionalidad que explica en mayor medida la fuerza/polaridad de los flujos que determinan su centralidad sobre el territorio. Diversos trabajos proponen, a partir de conjuntos relativamente homogéneos de funciones de intermediación, una tipificación de los diversos roles de estas ciudades, a los efectos de encontrar una explicación a la dispar evolución de los centros intermedios en el marco de un sistema urbano. En efecto, si bien se reconoce una relativa estabilidad en la

Geo UERJ - Ano 15, no. 24, v. 1, $1^{\circ}$ semestre de 2013 p. 339-370

ISSN: 1415-7543 E-ISSN: 1981-9021

http://www.e-publicacoes.uerj.br/index.php/geouerj 
jerarquía urbana (Henderson, 1997; Hildreth, op. cit.), puede observarse una variación en el alcance e intensidad en los flujos (de personas, bienes, empresas, etc.) que los distintos centros urbanos atraen (y/o retienen) desde diferentes escalas espaciales $y$, por lo tanto, con ello hay ciudades que ganan y ciudades que pierden.

En segundo lugar, cabe conocer qué tipo de funcionalidades caracterizan a las ciudades intermedias que han ampliado su influencia territorial, e incrementado la intermediación de flujos tanto en su contigüidad territorial, como con el resto del mundo, más allá del sistema urbano nacional y su jerarquía. Se acuerda -en general- que son las funcionalidades avanzadas las que generan una intensificación de las conexiones de largo alcance de diferentes flujos de conocimiento, personas y bienes, en la medida en que inducen densidad y complejidad a la estructura productiva y tecnológica localizada y, al mismo tiempo, atraen y/o retienen recursos humanos calificados.

De este modo, una parte importante de la discusión sobre la trayectoria de las ciudades intermedias pasa por identificar el cumplimiento de estas funciones, su evolución y la evaluación de cuáles son las que sostienen su centralidad. En los casos que ha abordado la investigación que inspira la presente ponencia, y teniendo en cuenta la especialización productiva regional en actividades intensivas en recursos naturales, cabe preguntarse entonces: cuáles son estas funciones avanzadas?, que relación tienen con los complejos productivos regionales y su trayectoria, y si son estas funciones las que "sostienen" y "redefinen" la centralidad económica de las tres ciudades? ${ }^{5}$

\section{Las ciudades intermedias y la estructuración del entorno rural}

El concepto de centralidad urbana necesariamente comprende el territorio inmediato que la ciudad organiza y estructura. En este sentido, según Jacobs (1971:9), el espacio rural se construye directamente sobre la base de la economía y trabajo urbanos. Las ciudades "inventan y reinventan la vida económica rural", puesto que en ellas se desarrollan los nuevos bienes y servicios, y las innovaciones destinadas al espacio rural (ibíd.: 137).

Esta visión, que concibe a las ciudades como los verdaderos motores de los procesos de desarrollo tanto urbano como rural, debe ser reconsiderada en el contexto de una realidad signada por nuevas formas de integración entre espacios urbanos y rurales, en la que, a partir de diferentes conceptos como desruralización, rururbanización o contraurbanización, es posible hilvanar un argumento que, en esencia, reinterpreta la relación campo-ciudad, marcando la creciente preeminencia de la dimensión urbana (Gorenstein et al., 2010:5). De este modo, se materializan nuevos y diferentes tipos de vínculos a partir de:

Geo UERJ - Ano 15, no . 24, v. 1, $1^{\circ}$ semestre de 2013 p. 339-370

ISSN: 1415-7543 E-ISSN: 1981-9021

http://www.e-publicacoes.uerj.br/index.php/geouerj 
- la complejización de la producción agrícola que se traduce en sistemas agroindustriales localizados simultáneamente en ámbitos rurales y urbanos;

- la revalorización de la vida rural que lleva a los habitantes urbanos a trasladar sus estilos de vida y demandas de nuevos servicios a las zonas rurales;

- la necesidad de fuentes alternativas de ingresos por parte de productores y trabajadores rurales, lo cual genera su interrelación con centros y demandas urbanas; y, finalmente,

- las crecientes migraciones "pendulares" entre el campo y la ciudad que generan un inédito grado de conexión e integración entre estos dos ámbitos (Olea, 2011: 17-18).

En definitiva, se van construyendo espacialidades y desarrollando procesos socioeconómicos que no pueden caracterizarse únicamente como urbanos o como rurales, motorizando una creciente interrelación, tanto en el plano analítico como en el político (Garrett, 2005; Manzanal, 2006; Kay, 2007; Castro y Reboratti, 2008). Esta integración también posee una fuerte dimensión cultural: la mayor difusión de los medios de comunicación tradicionales (radio y televisión) y la explosión de los nuevos medios de comunicación (telefonía móvil e internet) intensifican la influencia de la cultura urbana y global en el medio rural (Kay, 2007:39).

En el caso de países como Argentina, las funciones de intermediación urbanas vinculadas con los territorios rurales siguen influenciadas por las dinámicas de la agricultura. Aun en un contexto de creciente complejización y heterogeneidad de los espacios rurales, este sector continúa desempeñando un rol fundamental en la evolución de aquéllos. ${ }^{6}$ Esto se expresa en los equipamientos e infraestructuras que se distribuyen en las áreas de interrelación rural-urbana, así como en las capitales y/o red de ciudades regionales donde se concentran las economías de aglomeración requeridas por estas actividades (Gorenstein et al., 2010:6).

De este modo, las funciones de las ciudades intermedias (provisión de servicios, localización de mano de obra, mercado de trabajo alternativo para la población rural, etc.) coexisten con otras al interior de la red de ciudades, mostrando una doble lógica derivada de las especificidades del sector agropecuario y, más en general, de las actividades intensivas en recursos naturales: por un lado, relaciones espaciales signadas por la contigüidad y el dominio de una ciudad relativamente próxima, y por otro, relaciones de superposición y articulación con otras escalas espaciales no definidas por la contigüidad, resultantes -sobre todo- de la configuración y dinámica de cadenas productivas globales.

Estas interacciones espaciales, entre las que se materializan las rururbanas, constituyen, entonces, otro plano analítico de los casos estudiados (pampeanos y patagónicos).

Geo UERJ - Ano 15, nº 24, v. 1, $1^{\circ}$ semestre de 2013 p. 339-370

ISSN: 1415-7543 E-ISSN: 1981-9021

http://www.e-publicacoes.uerj.br/index.php/geouerj 


\section{Dinámicas de aglomeración y terciarización de la estructura económica y ciudades intermedias}

\section{Economías de aglomeración}

La "ciudad" ha constituido el espacio tradicional de concentración de la gestión de las relaciones personales, sociales y de poder en la historia de la humanidad, (Camagni, 2005:21). Como es sabido, en la teoría económica, desde los trabajos pioneros de Marshall, se reconocen las ventajas de la concentración espacial de la actividad económica, sentando las bases sobre las que luego se irán focalizando los estudios sobre los efectos de las economías externas generadas por los territorios. Si bien sus estudios profundizaban el análisis de la industria como fenómeno histórico relevante, recobraban identidad analítica dos categorías centrales de la economía territorial: la localización espacial y la innovación tecnológica en el marco de la "atmósfera productiva".

El autor, en sus estudios de fines del siglo XIX, detectó que los establecimientos industriales que producían bienes similares tendían a localizarse muy próximos unos de otros formando ciudades manufactureras o distritos industriales. Su localización estaba determinada por condiciones físicas, tales como las características del suelo y las facilidades de comunicación, pero también por acciones políticas. Su crecimiento se debía a la presencia de un conjunto de condiciones que posibilitaba la aparición de una serie de efectos virtuosos que potenciaban la presencia de rendimientos crecientes (Marshall, 1972:Cap. X). Esto le condujo a sostener que, al menos en determinados sectores productivos, las ventajas de la producción a gran escala pueden obtenerse no sólo a partir de la concentración de la producción en grandes establecimientos sino, también, en el agrupamiento espacial de un gran número de pequeños productores. Esto posibilita la existencia de economías externas a la empresa pero internas a la industria, lo cual permite la emergencia de rendimientos crecientes aun manteniendo los principios de los modelos de competencia perfecta.

Desde los aportes de Marshall, el sector manufacturero pasó a ser estudiado como motor del desenvolvimiento económico, fundamentalmente por dos razones. Por una parte, por la creciente explotación de las economías de escala y la mecanización y rutinización de las tareas. Y por otra, desde la perspectiva territorial, las actividades manufactureras emergían como el sector productivo con mayor movilidad espacial y, con ello, más permeable al impacto de políticas de desarrollo regional. De este modo, en un sentido general, las reflexiones de Marshall aportaron a lo que, más tarde, permitió fundar una categorización de las economías de aglomeración; considerando su génesis en relación con la empresa, distingue entre internas y externas (Muñiz Olivera, 1998; Camagni, 2005).

Geo UERJ - Ano 15, nº. 24, v. 1, $1^{\circ}$ semestre de 2013 p. 339-370

ISSN: 1415-7543 E-ISSN: 1981-9021

http://www.e-publicacoes.uerj.br/index.php/geouerj 
Los rendimientos crecientes generados al interior de la empresa, representados por las economías internas de escala, se traducen en la posibilidad de utilizar un conjunto de activos que permite obtener un costo medio mínimo decreciente con la cantidad producida. La concentración espacial de potenciales demandantes -es decir el área de mercado del bien o servicio cuya función de producción presenta rendimientos crecientes- se constituye en un atractivo locacional y, en términos de Krugman (1991, 1996), representa una de las principales fuerzas centrípetas de los territorios.

Las externalidades emergentes en las aglomeraciones productivas y residenciales se diferencian, a su vez, en economías de localización y economías de urbanización. Las primeras caracterizan los beneficios que puede obtener una empresa de un sector por ubicarse en la proximidad de otras que, también, pertenecen al mismo sector. Estos beneficios, externos a la empresa pero internos a la industria, han sido adecuadamente descriptos por Marshall, y están relacionados con la existencia y densidad local de servicios especializados, un mercado de trabajo local cualificado, especialmente en el sector de referencia, y la presencia de externalidades cognoscitivas, u ósmosis tecnológica, asociadas a un sector determinado. Y las segundas, externas a la empresa y al sector, ofrecen iguales oportunidades de ser rentabilizadas por cualquier empresa de cualquier sector. Estas externalidades tienen una estrecha relación con el tamaño de la aglomeración y, en su contenido, reconocen dos vertientes. Una, derivada de la tradición más clásica, con referencia en Isard (1973), que enfatiza en la disponibilidad de mano de obra multifuncional o polivalente y de infraestructura y servicios públicos; y la otra, extendida a partir de Jacob (1971), focaliza en los beneficios emergentes de ambientes productivos diversos, que favorecen la integración vertical y la densificación de la trama productiva urbana.

Una categorización alternativa de las economías de aglomeración fue propuesta por Scitovsky (1954), distinguiendo entre economías externas pecuniarias y no pecuniarias. Las primeras recogen los efectos que conducen a que una función de producción determine costos medios más bajos en un territorio que en otro, afectando positivamente la función de beneficios. Las externalidades no pecuniarias, definen los beneficios que no son capturados por los precios pero que, traducidos en innovaciones tecnológicas, posibilitan cambios en la función de producción y la obtención de menores costos medios.

Estas dos categorías de economías de aglomeración se relacionan estrechamente con las categorías economías de aglomeración estáticas y dinámicas, definidas por su efecto sobre la función de producción. En tal sentido, las economías estáticas identifican los beneficios que el territorio aporta a la reducción de costos medios, generando una ventaja comparativa para las

Geo UERJ - Ano 15, no . 24, v. 1, $1^{\circ}$ semestre de 2013 p. 339-370

ISSN: 1415-7543 E-ISSN: 1981-9021

http://www.e-publicacoes.uerj.br/index.php/geouerj 
empresas allí localizadas. Por su parte, las externalidades dinámicas recogen las contribuciones del territorio al proceso de innovación de las empresas radicadas en ese espacio, permitiendo la emergencia de ventajas competitivas asociadas a esos beneficios. Ellas adquieren una relevancia creciente en los estudios territoriales contemporáneos ${ }^{7}$.

Ahora bien, el debate teórico acerca de los efectos de las economías de aglomeración adquiere una dimensión muy diferente para las metrópolis y ciudades intermedias de América Latina y otras regiones periféricas. La compleja combinación de la industrialización trunca, la posterior desindustrialización, y la terciarización polarizada, modifican la estructura urbana preconfigurada por las relaciones y procesos de organización social (Pradilla, 1984: Cap. I) e imponen nuevos condicionantes.

Por ejemplo, siguiendo a Borello et al. (2009),

"para el caso de muchos países como la Argentina, a diferencia de algunas regiones virtuosas en otros países, muchas de las economías externas (en especial las no pecuniarias) no se concretizan, no se hacen realidad a pesar de que en muchos casos hay un potencial para que esto suceda".

Al respecto, en su estudio sobre la Región Metropolitana de Buenos Aires, el autor, menciona cuatro causas, a saber: no hay interacción entre universidades, centros tecnológicos y empresas; la oferta tecnológica disponible tiende a estar poco orientada a identificar las necesidades específicas; muchas empresas no tienen las capacidades necesarias para acceder a ciertos conocimientos; y, en la interacción, se registran problemas serios de traducción tecnológica.

Si se acepta que estos elementos describen en forma adecuada la realidad de las metrópolis latinoamericanas, de inmediato surge el interrogante acerca de la posibilidad de conformación de clusters industriales o, en nuestro caso, los agrupamientos en torno a recursos naturales en realidades urbano-regionales no metropolitanas. Es muy probable que en estos casos, las problemáticas mencionadas por Borello se acentúen. En tal sentido, y a los fines de la investigación, se ha avanzado en caracterizar las potencialidades y restricciones de las fuerzas aglomerativas que operan en estos centros, así como las funciones urbanas que los mismos desempeñan.

\section{Tercerización de la base económica urbana}

Las transformaciones marcadas por la flexibilización y fragmentación del proceso productivo y el avance de las tecnologías de información y comunicación (TIC), como vector de innovación en otros sectores de la economía, van delineando una profunda metamorfosis en las economías

Geo UERJ - Ano 15, nº 24 , v. 1, $1^{\circ}$ semestre de 2013 p. 339-370

ISSN: 1415-7543 E-ISSN: 1981-9021

http://www.e-publicacoes.uerj.br/index.php/geouerj 
territoriales, impactando sobre su organización interna, su morfología, su entorno y, en términos generales, la competitividad de empresas y territorios a nivel mundial.

Los nuevos patrones productivos que dan cuenta de un intenso proceso de terciarización se han ido extendiendo progresivamente a los países en desarrollo donde, superpuestos a las tradicionales disparidades regionales, han generado procesos simultáneos de inclusión y exclusión en los que conviven empleos de alta productividad, asociados al terciario superior y a la competitividad sistémica, con otros de baja productividad y mala calidad (Weller, 2004). Dadas las especificidades de las actividades de servicios, se plantean nuevas miradas teóricometodológicas acerca de la dinámica económica que ellas pueden imprimir en el medio urbano en el marco de la relación entre terciarización y urbanización en distintos tipos de países y regiones. ${ }^{8}$

Dentro de este sector tan heterogéneo, son aquellas actividades más integradas e interrelacionadas con el sistema productivo -por caso los denominados "servicios a la producción", principalmente los Servicios Avanzados a las Empresas (SAE)- las que vienen desempeñando un papel fundamental en los últimos años, debido a su rol estratégico como factor de "desarrollo" en contextos de creciente competitividad territorial (Asián Chaves, 2002 b:1).

Esta situación, que se traduce en la mayor significación de las actividades terciarias, tanto en el valor de la producción como en el empleo, ha reforzado la concepción de los servicios no solo como complementos pasivos de la localización industrial y residencial, sino como un elemento fundamental en la creación de un ambiente favorable a la atracción de nuevas actividades económicas en una región. ${ }^{9}$

Asimismo, con la innovación tecnológica emergieron nuevos servicios a las personas y a las empresas. Los primeros se asocian al aumento de la participación del consumidor en las operaciones de servicios, producto de las nuevas tecnologías y la creación de nuevas necesidades resultantes de la globalización. Y los SAE, intensivos en conocimiento, atienden necesidades específicas de empresas y organismos del sector público, e impactan positivamente en las ganancias de productividad de los clientes, en particular de las empresas industriales y de las administraciones públicas, generando un efecto multiplicador en otros sectores. ${ }^{10} \mathrm{Se}$ constituyen, así, en agentes centrales del proceso de innovación territorial dado que funcionan como fuentes de innovación, cuando inician y desarrollan actividades de innovación en sus organizaciones clientes; como facilitadores de innovación cuando ayudan a las organizaciones en sus propios procesos de innovación; y como transportadoras de innovación cuando ayudan en

Geo UERJ - Ano 15, nº 24, v. 1, $1^{\circ}$ semestre de 2013 p. 339-370

ISSN: 1415-7543 E-ISSN: 1981-9021

http://www.e-publicacoes.uerj.br/index.php/geouerj 
la transferencia del conocimiento existente entre organizaciones, sectores y redes (Innobasque, 2009: 3-4).

De este modo, el tipo de función desempeñado por dichos Servicios dependerá, parcialmente, de la respuesta de la organización cliente, de su grado de integración con el proveedor, y de su capacidad de absorción, aprendizaje y gestión del conocimiento.

El desarrollo de estos servicios -que encuentra en las ciudades los sitios preferidos para su producción- ha ido redefiniendo las funciones de las aglomeraciones urbanas (Sassen, 1998 y 2010) y construyendo nuevas estructuras geográficas y formatos urbanos (Polése y Rubiera Morollón, 2009:278). Una vasta literatura específica ${ }^{11}$ reconoce la importancia de los SAE en el desarrollo competitivo del tejido industrial, asociándolos a una fuerte elevación de la productividad que reestructura la división internacional y social del trabajo y la estructura y dinámica de los empleos e ingresos.

Una vez más, cabe advertir sobre el traslado lineal de los efectos positivos de la expansión de los SAE evidenciada en las áreas centrales a las áreas periféricas, en las que se detectan disparidades regionales y de la renta. En la actual economía servo-industrial, las actividades de servicios más ligadas a los cambios tecnológicos en curso posibilitan el desarrollo de un nuevo y denso tejido industrial, funcional a la acumulación capitalista. Son los países y regiones centrales los que lideran estas dinámicas que, en torno a la relación de los SAE con la competitividad del tejido empresarial, muestra diferencias con los registros en los territorios periféricos (Asián Chaves, 2002 b:1).

En tal sentido, diversas investigaciones dan cuenta de que existe una tendencia por parte de las prestadoras de SAE a concentrarse en los espacios geográficos de mayor renta, atraídos por un conjunto de externalidades derivadas del principio de aglomeración, entre las que se destacan la disponibilidad de recursos humanos calificados y de informaciones generales y específicas, el transporte, la accesibilidad y las posibilidades de comunicación, y la densidad del entorno económico y social. (Jouvaud, 1995:8-12); mientras otros servicios tradicionales o "atrasados" se localizan de forma más difusa sobre el territorio (Asián Chaves, 2002 a: 4). ${ }^{12}$

Los estudios empíricos referidos a los Servicios Avanzados a Empresas en ciudades intermedias de la periferia son escasos. No obstante, no pueden desconocerse los condicionamientos históricos, económicos, sociales y culturales propios de entramados productivos y empresariales de escasa complejidad.

Por su parte, cuando hablamos de centros ligados a actividades intensivas en recursos naturales, podrían esperarse dos tipos de tendencias, teniendo en cuenta la continuidad del patrón

Geo UERJ - Ano 15, nº 24, v. 1, $1^{\circ}$ semestre de 2013 p. 339-370

ISSN: 1415-7543 E-ISSN: 1981-9021

http://www.e-publicacoes.uerj.br/index.php/geouerj 
locacional en función de la distribución de estos recursos. Por un lado, que se replique la atracción de actividades de servicios, incluyendo los avanzados, en función de la proximidad con las empresas ligadas a las actividades primarias. Por otro lado, frente al cambio de paradigma tecnológico y, entre otros aspectos, la dilución del "efecto distancia", la posibilidad de proveer estos SAE desde aquellos ámbitos urbanos que concentran las actividades comando del sistema en su conjunto.

\section{Trayectorias y renovación en ciudades intermedias}

\section{La dependencia de la trayectoria}

El debate reciente sobre la dinámica económica de las ciudades y regiones ha permitido profundizar la investigación respecto de los orígenes de las diferentes trayectorias que se observan en los territorios. Se destacan, en este aspecto, los aportes de las corrientes teóricas asociadas a los distritos industriales, milleiux innovador, regiones de aprendizaje que rescatan las causas endógenas que propician u obstaculizan las actividades innovadoras, y asocian dichos factores a la diferente dinámica institucional local (Moulaert y Mehmood, 2008). Esta visión ha sido cuestionada a partir de resaltar ciertas insuficiencias o lagunas teóricas existentes en su aproximación a la dinámica de las regiones, especialmente por relegar cuestiones vinculadas al marco de heterogeneidad que proyecta la dinámica globalizadora sobre los diferentes espacios subnacionales. En este sentido, se trata de recuperar temas centrales de la economía política del desarrollo regional, entre los que se incluye la importancia que la trayectoria económica de los territorios proyecta sobre su evolución.

Desde esta perspectiva, diferentes autores han rescatado el concepto de path dependence ${ }^{13}$ en el campo de la economía regional, de forma de incorporar la importancia de la historia y su influencia en las trayectorias urbano/regionales. El concepto de path dependence, desarrollado originalmente por B. Arthur y P. David en sus estudios de evolución tecnológica, está presente en la mayor parte de los modelos de la teoría evolucionista, y su utilización se ha extendido desde el ámbito de la tecnología a la macroeconomía, la ciencia política, la dinámica urbana y regional, entre otros.

La incorporación de este concepto se vincula a la adopción de una visión dinámica en el estudio de los procesos económicos, cuyo propósito es explicar el movimiento en el tiempo o, en otras

Geo UERJ - Ano 15, no . 24, v. 1, $1^{\circ}$ semestre de 2013 p. 339-370

ISSN: 1415-7543 E-ISSN: 1981-9021

http://www.e-publicacoes.uerj.br/index.php/geouerj 
palabras, por qué nuestro objeto de estudio es lo que es en un momento del tiempo en términos de cómo llegó a serlo (Dosi y Nelson, 1994). Escritos que rescatan su pertenencia a las teorías heterodoxas (postkeynesianos evolucionistas institucionalistas, marxistas) frecuentemente adoptan la expresión path dependence como sinónimo de la importancia que alcanza la historia en la evolución de los procesos económicos, especialmente cuando se intenta poner de manifiesto la relevancia de eventos pasados sobre las acciones presentes y futuras (Schreyogg y Sydow, 2010).

Aunque el concepto es utilizado en general como metáfora de history matters, el importante crecimiento en la utilización de la expresión path dependence ha significado, simultáneamente, una cierta imprecisión sobre su verdadero significado teórico. Así, es preciso dotar al término path dependence de un consistente análisis de las causas que determinan la dependencia de la trayectoria y de sus implicancias para las opciones actuales y futuras del objeto de estudio, separándolo de ciertas connotaciones que no necesariamente deben vincularse. ${ }^{14}$

En esta búsqueda de una mayor precisión conceptual, David (2006) asevera que un "proceso dinámico cuya evolución es gobernada por su propia historia es path dependent" y destaca la importancia de profundizar en la investigación de cada caso para determinar las causas que llevan a un proceso dinámico a ser influenciado en sus opciones futuras por el sendero recorrido.

Para incorporar el concepto de path dependence en la ciencia regional, Hodgson (2002) agrega otra dimensión que puede interpretarse como relevante, en la medida en que postula la necesidad de considerar determinantes históricos y/o geográficos en la teoría de la dinámica económica $^{15}$, lo que permite asociar el tiempo y el espacio.

En una línea similar, Martin y Sunley $(2006,2010)$ afirman que la combinación de la dimensión histórica proveniente de la utilización del concepto de path dependence debería unirse a las especificidades locales, dando lugar a una teoría place dependent de la trayectoria de una ciudad o región. En este sentido, estos autores sostienen que es posible pensar que la maduración tecnológica y del producto de la industria dominante del lugar jugará un papel clave en dar forma a la trayectoria relevante de la economía regional, aunque esta relación tan simple y directa no puede tomarse en un sentido determinista ya que se vería atenuada por otros factores según muestran diversos estudios empíricos:

- diferentes evoluciones de clusters sectoriales ubicados en distintas regiones, supone procesos de adaptación y reconversión alternativos;

Geo UERJ - Ano 15, no . 24, v. 1, $1^{\circ}$ semestre de 2013 p. 339-370

ISSN: 1415-7543 E-ISSN: 1981-9021

http://www.e-publicacoes.uerj.br/index.php/geouerj 
- diferencias en los procesos maduración de los cluster originadas en las estrategias de las firmas locales, la dinámica del sector y el contexto urbano y regional;

- la evolución independiente de diferentes sectores, según el grado de multiple related path dependence que pueda verificarse en la economía regional, puede dar origen al surgimiento de nuevos sectores que comiencen a proyectar una nueva dinámica sobre el territorio.

Si bien el análisis evolucionista al cual está vinculada la concepción de dependencia de la trayectoria es relevante para entender la dinámica territorial, el estudio del desarrollo de fenómenos socialmente complejos como son las regiones no debería quedar circunscripto al análisis de las firmas, los agentes y los sectores (Mc Kinnon et al., 2009). Esta reflexión induce a recuperar la dinámica económica regional, a partir de incorporar las restricciones y posibilidades que se infieren a partir de las trayectorias históricas seguidas por los procesos de la economía global (Gutman y Gorenstein, 2003).

\section{Cambios y/o continuidades en la trayectoria}

La incorporación de la dimensión global de los procesos económicos no puede dar lugar a un enfoque determinista y generalizador del análisis de las posibilidades de diversificación de los territorios, aun en los casos en que el desarrollo de un importante complejo vinculado a los recursos naturales deja una fuerte impronta en la dinámica urbano/regional. Por el contrario, es en la especificidad de la integración de los territorios a la economía global donde se encuentra la diferente capacidad de las regiones y ciudades para promover procesos de diversificación económica. En las tres ciudades comprendidas en el presente estudio, resulta interesante la posibilidad de contrastar el desempeño de sus estructuras económicas a la luz de una taxonomía que permita evaluar las posibilidades de cambios y complejización (Simmie et al., 2008). Se trata de centros que, por un lado, se desempeñan como nodos regionales con funciones relacionadas con los complejos intensivos en recursos naturales de sus entornos territoriales; y por otro, son ciudades en las que se concentra una masa crítica de instituciones políticas, sociales y de investigación y desarrollo conformando, en un sentido general, el umbral mínimo de las economías de aglomeración clásicas y dinámicas analizadas anteriormente.

Desde esta perspectiva, entendemos que las opciones de incorporación de actividades con potencial de producir cierta densificación de la estructura económica pueden caracterizarse a partir de las siguientes dimensiones:

- mejora en la integración actual del sector clave: upgrading de industrias existentes o integración de nuevas empresas que permitan incorporar avances tecnológicos o empresariales para agregar valor en la cadena regional, dando lugar a un nuevo conjunto de actividades,

Geo UERJ - Ano 15, nº 24, v. 1, $1^{\circ}$ semestre de 2013 p. 339-370

ISSN: 1415-7543 E-ISSN: 1981-9021

http://www.e-publicacoes.uerj.br/index.php/geouerj 
- diversificación relacionada: posibilidades de diversificación en industrias y sectores relacionados con la base actual de la economía regional, a partir de sistemas de spin-off de las firmas principales o de proyección de un conjunto de empresas proveedoras de bienes o servicios a la actividad principal,

- capacidad de diversificación no relacionada: potencial de innovación por parte de firmas, agentes y organizaciones (universidades, agencias de investigación y extensión, programas gubernamentales de estímulo al desarrollo productivo) del territorio que puedan dar origen a una ampliación de la base productiva en sectores que signifiquen una diversidad no relacionada con el sector ya dominante, incluyendo las posibilidades de radicación de empresas extra-locales,

- factores políticos y mecanismos de regulación económica, que promueven una inserción del espacio subnacional en la economía nacional e internacional a partir de la inversión en nuevos sectores, $\mathrm{y}$

- procesos asociados al regionalismo, reflejados en acciones de los agentes del territorio como formas cooperativas/asociativas que permitan una actitud reflexiva de los agentes locales para determinar nuevas estrategias y acciones de desarrollo.

Con todo, es importante tener presente que el potencial de diversificación de las ciudades vinculadas a los recursos naturales en Argentina, interactúa con ciertas condiciones derivadas del funcionamiento del sistema económico nacional:

- en los sectores intensivos en recursos naturales, ${ }^{16}$ un país como Argentina es eficiente en las fases iniciales del proceso productivo y en productos poco elaborados, ello devenido de un esquema de ventajas comparativas del sector primario. Pero, a medida que se avanza en estas cadenas productivas, en fases productoras de bienes con mayor grado de transformación, diferenciación, sofisticación tecnológica, etc., la capacidad competitiva disminuye;

- en una trayectoria asociada al modelo de desarrollo económico territorial del país, los sectores industriales difusores del progreso tecnológico (maquinarias y herramientas, electrónica, telecomunicaciones, biotecnología, etc.), tienden a reconcentrarse en el ámbito metropolitano;

- las políticas nacionales de promoción productiva han gestado ciertos procesos de deslocalización industrial en regiones extra-pampeanas que no siempre logran generar una posterior integración de las cadenas productivas asociadas.

A partir de las consideraciones teóricas expuestas, ciertas cuestiones pueden ser consideradas centrales a la hora de indagar en el funcionamiento económico-territorial de centros no metropolitanos, conceptualmente identificados como intermedios.

Geo UERJ - Ano 15, nº. 24, v. 1, $1^{\circ}$ semestre de 2013 p. 339-370

ISSN: 1415-7543 E-ISSN: 1981-9021

http://www.e-publicacoes.uerj.br/index.php/geouerj 
En primer lugar, y desde la perspectiva de la centralidad urbana, el sostenimiento de su posición y/o ascenso en la jerarquía urbana, tiene que ver con la "fuerza" que ejerce a través de las funciones de intermediación avanzadas. En este marco, Hildreth (2006) discute sobre la posibilidad de que estas funciones se puedan desarrollar en estos ámbitos y, siguiendo a Henderson (1997), argumenta que los SAE, las industrias conocimiento intensivas, así como la generación de nuevo conocimiento productivo requieren (entre otras cuestiones) de la existencia de economías de urbanización ${ }^{17}$, pero -por sobre todo- de las capacidades locales para aprovecharlas. Estas últimas dependen del tipo de trayectoria previa: los centros con un desarrollo en los SAE obtienen mayores externalidades positivas de la aglomeración que aquellos cuya economía se basa en una o relativamente pocas industrias o en la explotación de determinados recursos naturales localizados; y las ciudades con una población económicamente activa (PEA) altamente calificada y una "cultura innovadora" tienden a aprovechar mejor las economías de localización.

En segundo lugar, retomando lo expuesto acerca de la variedad de economías de aglomeración (internas/externas a la industria, estáticas/dinámicas), existe una amplio consenso en torno a que los SAE, en tanto que en parte son genéricos (comparten cierta matriz de conocimiento productivo/práctico común), se favorecen de un ambiente con un umbral crítico de empresas. En este sentido, la presencia de universidades y/o centros de investigación y desarrollo puede generar desprendimientos productivos a partir de una acumulación importante de servicios de transferencia tecnológica en el entorno.

Volviendo a los territorios y su dependencia de determinadas trayectorias productivas cabe plantearse una serie de interrogantes:

¿Qué tipo de servicios y recursos humanos calificados se demandan en territorios caracterizados por la presencia de unas pocas industrias manufactureras (de productos maduros) o de explotación de recursos naturales?

¿En qué medida esta demanda explica la composición de esta dotación urbana (recursos calificados, infraestructuras especializadas, servicios avanzados)?

¿Es posible pensar en procesos económicos e institucionales autónomos, derivados de los nuevos tipos de intermediación urbano-territorial, que motorizan otros flujos y modalidades de utilización de estas dotaciones urbanas?

La investigación desarrollada, particularmente en lo referido a las trayectorias económicas de las tres ciudades bajo estudio, ha procurado aproximar respuestas a estos interrogantes.

\author{
Algunas conclusiones y reflexiones acerca de los resultados obtenidos en la investigación \\ Geo UERJ - Ano 15, n. 24, v. 1, $1^{\circ}$ semestre de 2013 p. 339-370 \\ ISSN: 1415-7543 E-ISSN: 1981-9021 \\ http://www.e-publicacoes.uerj.br/index.php/geouerj
}


La pregunta planteada: ¿qué tipo de intermediación ejercen las ciudades estudiadas?, puede responderse apelando al recorrido analítico de las cuestiones estudiadas en la investigación, y plantea, al menos, tres ejes de reflexión sobre las ciudades intermedias -Bahía Blanca, Río Cuarto y Neuquén- que funcionan como centros regionales pampeanos y norpatagónicos. ${ }^{18}$

El primero de ellos refiere a la funcionalidad de estos núcleos urbanos, los cambios que se han producido a lo largo de su trayectoria, y los factores que los motorizaron. El segundo eje gira en torno a la composición de la estructura económica de estas ciudades, proporcionando elementos de análisis y discusión sobre la dinámica que imprimen las actividades intensivas en recursos naturales como fuente de demanda de los mercados de bienes, servicios y de trabajo. Por último, el tercer eje analítico focaliza en el sistema local de innovación como motor del cambio en la función de intermediación urbana, además de su articulación o no con dichas actividades de especialización regional.

\section{Intermediación y estructuración del territorio}

El interrogante acerca de si ¿han ampliado su influencia económico-territorial? Permite señalar que: en las tres ciudades, la centralidad, dadas sus respectivas posiciones geográficas, se fue fortaleciendo a partir de los diferentes tipos de conexión (intra e inter-regional) y de los roles de intermediación desempeñados desde fines del siglo XIX. Así, mientras Bahía Blanca y Río Cuarto revelan, con sus especificidades, la existencia de rasgos genéticos originados durante la vigencia del esquema agroexportador pampeano, la ciudad de Neuquén da cuenta de una progresiva centralidad asociada a las actividades de exploración, extracción y aprovechamiento de los recursos naturales del suelo y el subsuelo de su entorno (petróleo, gas, minerales no metalíferos, agua dulce, rocas y madera) que se desarrollaron particularmente para abastecer la emergencia y expansión de la industria nacional en la etapa sustitutiva, y a posteriori en el marco de políticas exportadoras, a su rol de interconexión (económica, política, institucional) en el territorio patagónico, y a la actividad gubernamental como capital del Territorio desde el fin del siglo XIX, y como capital de la provincia del mismo nombre, desde mediados de la década del cincuenta del siglo pasado.

Las tres ciudades están ubicadas en puntos estratégicos del sistema urbano (nacional, provincial y regional); detentan condiciones relativas favorables en términos de transporte y comunicación; ejercen su centralidad en el nivel interurbano y regional; proveen bienes y servicios a estos ámbitos, a la vez que se constituyen en fuente de demanda de productos y servicios del ámbito rural circundante, y de las áreas turísticas cordilleranas de los lagos en el caso neuquino; entre otras importantes (culturales, gubernamentales, etc.). En suma, detentan economías de

Geo UERJ - Ano 15, no . 24, v. 1, $1^{\circ}$ semestre de 2013 p. 339-370

ISSN: 1415-7543 E-ISSN: 1981-9021

http://www.e-publicacoes.uerj.br/index.php/geouerj 
aglomeración en un sentido amplio, al tiempo que poseen la escala urbana (media) teóricamente más favorable para enfrentar los costos asociados a la urbanización.

Ahora bien, cuando se explora la dinámica de estas funciones desde la perspectiva de su intensidad y alcance territorial, aparecen diferencias asociadas a cuestiones geográficas, históricas e institucionales. Neuquén, ubicada en el norte occidental de la Patagonia, fue poblada como área próxima a la frontera con Chile. Ello justificó la construcción ferroviaria y de infraestructura vial que la conecta a la pampa húmeda, y la disponibilidad de recursos energéticos promovió las grandes obras hidroeléctricas y los aprovechamientos de hidrocarburos que acompañaron la fase de expansión industrial nacional. Sumado a ello, la actividad gubernamental, la radicación de planteles de trabajadores jóvenes nacionales y extranjeros, el crecimiento financiero e inmobiliario, y el desarrollo turístico cordillerano enlazado con el intercambio con Chile la convirtieron en un nodo regional metropolitano, con funciones de intermediación más complejas y de mayor alcance espacial. Tal como se señala en el estudio respectivo, esta ciudad hoy funciona como centro económico, social, político, financiero y cultural del territorio norpatagónico. Y este proceso se asocia al factor capitalidad y a las redefiniciones en la operatoria de los complejos de hidrocarburos, minería, turismo y fruticultura, como parte de cadenas globales. ${ }^{19}$

Bahía Blanca, en cambio, ha ido reduciendo su influencia geográfica hacia adentro -de nodo extendido a la región patagónica ha pasado a nodo regional de proximidad, (sudoeste de la provincia de Buenos Aires)-, conservando las funciones características de las agro-ciudades pampeanas y sosteniendo su nodalidad nacional por la superposición y articulación con otras escalas espaciales no definidas por la contigüidad, derivadas, sobre todo, de la actividad portuaria (ligada a los agronegocios) y la petroquímica. La ciudad de Río Cuarto mantiene su statu quo de centro regional de proximidad, también con funciones de intermediación típicas de los centros del interior pampeano, en el marco de los cambios que se producen en el uso del espacio rural y la gestión de la producción agropecuaria regional.

En suma, estas dinámicas territoriales ilustran que el atributo "medio" está muy lejos de asegurar un sendero urbano unidireccional. La inmutable de Río Cuarto, la creciente de Neuquén y, su contracara, en Bahía Blanca, replican las diferentes situaciones -centros que "ganan" o "pierden"- que se manifiestan en el sistema urbano nacional a lo largo de su evolución y en el marco de la impronta económica, social y territorial que deriva de los esquemas de acumulación y crecimiento.

\section{Estructura económica y trayectoria reciente}

Geo UERJ - Ano 15, nº 24, v. 1, $1^{\circ}$ semestre de 2013 p. 339-370

ISSN: 1415-7543 E-ISSN: 1981-9021

http://www.e-publicacoes.uerj.br/index.php/geouerj 
Otro interrogante planteado refiere a ¿Cuál es la composición y dinámica de las bases económicas urbanas? ¿Se produjeron cambios sustantivos en el período de la posconvertibilidad?

En los estudios realizados se presentaron en forma estilizada los principales hitos en la trayectoria económico-territorial de las tres ciudades, articulando los elementos más destacados del comportamiento socioeconómico en el período reciente. De ahí se desprende que la economía de los centros pampeanos -Bahía Blanca y Río Cuarto- históricamente ha estado vinculada a la logística de la producción agropecuaria regional, al reciclaje de parte del excedente generado por ella y, en un sentido más general, con la provisión de bienes y servicios demandados por las poblaciones del entorno regional más inmediato. El centro bahiense refleja, asimismo, efectos diferenciales derivados de la mayor dimensión y diversificación de su aparato manufacturero, sumado a la localización de los complejos petroquímico y portuario. La economía neuquina, por su parte, responde a la dinámica que imprimen las actividades intensivas en recursos naturales propias de esta región: energéticos, mineros, del turismo y la fruticultura, sumado a la significación de la función gubernamental por su carácter de capital provincial.

Dos importantes rasgos comunes se manifiestan en el comportamiento de las tres economías urbanas. Por un lado, la circulación de la renta (agraria o hidrocarburífera) adquiere un rol preponderante como fuente de la demanda agregada. En este contexto, el nivel de empleo en las ciudades está fuertemente determinado por la demanda regional, definida de manera relevante por la magnitud monetaria del excedente registrado en la producción de los commodities; y sus efectos expansivos o de retracción se traducen en el desempeño de los sectores de servicios, comercio y actividad de construcción.

En este sentido, y desde la perspectiva del proceso de acumulación local, la transnacionalización, concentración y centralización del capital que se observa en los hidrocarburos, o en el complejo petroquímico-portuario en el caso de Bahía Blanca, no es neutral. Se trata de resortes clave, tanto por la magnitud de los excedentes que se territorializan, como en términos estratégicos por la capacidad de incidir en las posibilidades de reproducción y diversificación local-regional. En el caso de Neuquén, el peso de las regalías energéticas como recurso público, y su utilización en obras, emprendimientos, y estímulos financieros para el desarrollo productivo, urbano, y de construcción de infraestructura, genera impactos diversos en la matriz socio-económica y otros efectos territoriales.

En el caso del excedente agropecuario, además de las repercusiones económicas inmediatas derivadas de sus fluctuaciones, no se pueden ignorar las implicancias urbanas de las profundas Geo UERJ - Ano 15, nº. 24, v. 1, $1^{\circ}$ semestre de 2013 p. 339-370 ISSN: 1415-7543 E-ISSN: 1981-9021 http://www.e-publicacoes.uerj.br/index.php/geouerj 
transformaciones que se han producido en las estructuras agrarias regionales (mayor concentración de la propiedad de la tierra; penetración de actores extra-regionales; nuevas tecnologías y cambios organizacionales en las cadenas productivas, entre otros importantes).

Con respecto al proceso de territorialización de la renta y sus evidencias en los tres casos, cabe advertir los efectos derivados de estrategias del capital inmobiliario que intensifican la puja por la apropiación de la tierra urbana y suburbana, con visibles consecuencias en materia de segregación socioterritorial. Ahora bien, la renta no solo se recicla en estas ciudades sino, también, en la forma de segundas residencias en las localidades turísticas más cercanas y/o en algunos núcleos rurales regionales revalorizados en el marco de las nuevas formas de integración rururbana (Gorenstein et al. 2006; 2005; Landriscini et.al 2007; Geymonat et al. 2005).

Otro rasgo común a estas economías urbanas es la significación del aparato público. Con sus particularidades, especialmente la mencionada dimensión de la función gubernamental en el caso neuquino, las actividades desarrolladas por el sector público en sus tres niveles -nacional, provincial y municipal- ejercen una fuerte tracción sobre la demanda urbana a través de su inyección salarial permanente. En el caso de Bahía Blanca, donde la información disponible permitió elaborar algunos indicadores, la masa salarial pagada por el sector público (Universidad, Gobierno local, Salud y Justicia) es más relevante que la que se obtiene con el funcionamiento de las principales actividades económicas privadas consideradas individualmente, entre las que se cuentan las grandes plantas manufactureras del complejo petroquímico. En el de Río Cuarto se advierte claramente el peso presupuestario, tanto de la Universidad Nacional como del Municipio. Y, en el caso neuquino, la actividad gubernamental muestra mayor peso aún en lo salarial, y a través de la ejecución de obras públicas y del funcionamiento de empresas estatales y emprendimientos público-privados (Energía, agua, petróleo y gas, forestal, etc.).

Conectado con lo anterior, se avanza en elementos que responden al interrogante: ¿cuáles son las nuevas dinámicas observadas en la posconvertibilidad? El análisis de los mercados urbanos de trabajo revela, básicamente, dos cambios de tendencia. En las tres ciudades se registra un incremento en los niveles de empleo, con levísimas alteraciones de la estructura ocupacional, y la reducción de los puestos de trabajo precarios con la consecuente mejoría en la calidad de los empleos generados. La evolución de la informalidad entre los dos períodos (convertibilidad y posconvertibilidad), da cuenta, sin embargo, de un proceso de consolidación con niveles que rondan la mitad de los ocupados urbanos.

Geo UERJ - Ano 15, nº. 24, v. 1, $1^{\circ}$ semestre de 2013 p. 339-370

ISSN: 1415-7543 E-ISSN: 1981-9021

http://www.e-publicacoes.uerj.br/index.php/geouerj 
En este sentido, y con mayor intensidad que en los restantes aglomerados del país, la magnitud y persistencia del sector informal urbano no hace más que traducir las tensiones derivadas del ciclo económico (expansivo o en declive) y la naturaleza de las actividades económicas que demandan empleo. Como se señala en documentos producidos en la investigación, mientras que durante los períodos recesivos se asocian a las actividades "refugio", en las fases económicas expansivas la informalidad laboral se vincula a dinámicas de tercerización y subcontratación relacionadas con las actividades que motorizan el crecimiento.

Por último, y teniendo en cuenta esta fase de crecimiento de la demanda urbana, cabe preguntarse sobre la naturaleza de las funciones de intermediación relacionadas con las actividades intensivas en recursos naturales. Queda claro que no se produjeron cambios significativos y que, como en el pasado, las tres ciudades solo desempeñan funciones genéricas y auxiliares, que no agregan valor a los commodities de especialización. Una vez más cabe advertir sobre el manejo exógeno de estos resortes económicos estratégicos y, en ese marco, el status alcanzado como ciudades intermedias es funcional pero no protagónico en la gestión de los recursos naturales de sus territorios. Ahora bien, esta posibilidad local necesariamente interactúa con ciertas condiciones del contexto que impone el esquema esencialmente extractivo que rige en Argentina, expresado en diferentes zonas y regiones con importantes, y revalorizadas, dotaciones de recursos naturales.

\section{Funciones de intermediación avanzada y Sistema de innovación local}

Respecto a si estas ciudades desarrollan funciones de intermediación avanzada?, y ¿cuáles son las características distintivas de los sistemas de innovación local?, el debate teórico contemporáneo sobre las funciones de las ciudades intermedias pone el acento en aquellas que, de un modo u otro, traccionan procesos innovativos y/o que realizan una contribución agregada a la aplicación de nuevas tecnologías en la estructura productiva local. Hay aquí puntos de análisis que, asumiendo los rasgos que caracterizan a las tres estructuras productivas urbanoregionales, contribuyen a identificar dinámicas específicas vinculadas a los sistemas de innovación local.

Por un lado, el dominio de las tecnologías de las industrias de procesos, adquirido en un área específica de dotación de recursos naturales (gas, hidrocarburos, commodities petroquímicos, aceites, etc.) se traduce en la presencia de áreas vinculadas de I\&D en el sistema científicotecnológico público. Es decir, estas cadenas productivas simplificadas, que imprimen en la estructura productiva local una moderada diversificación relacionada ${ }^{20}$ produjeron la maduración de una trayectoria tecnológica estrechamente asociada a esta perfomance regional ${ }^{21}$. No pueden ignorarse, entonces, los efectos disruptivos derivados de los procesos privatizadores Geo UERJ - Ano 15, n . 24, v. 1, $1^{\circ}$ semestre de 2013 p. 339-370 ISSN: 1415-7543 E-ISSN: 1981-9021 http://www.e-publicacoes.uerj.br/index.php/geouerj 
y la naturaleza exógena de las innovaciones incorporadas en la producción agropecuaria y energética (nacional y regional) en los años recientes.

Por otro lado, en los tres sistemas de innovación se observa una tendencia creciente en áreas vinculadas a las nuevas tecnologías (TICs, bio y nanotecnología y nuevos materiales). La investigación en curso a hallado evidencias que, en rasgos estilizados, podrían resumirse en: destacado potencial científico y tecnológico alojado en el ámbito universitario; incidencia de la política pública reciente que estimula el desarrollo de estos campos y la conformación de spillovers entre las universidades locales y empresas (nacionales, regionales, e incluso internacionales); y debilidades endógenas que inciden sobre la posibilidad de transmisión de nuevos conocimientos e información a lo largo de las estructuras productivas urbano-regionales. Entre estas debilidades, y según surge de la aproximación realizada en las dos ciudades pampeanas, vale la pena mencionar la escasa sinergia del entramado institucional empresarial, que manifiesta interacciones vaciadas de contenido específico, sumado a la debilidad de las áreas de vinculación con el sistema científico-tecnológico. Algo similar resulta de estudios realizados sobre el tejido empresario neuquino. ${ }^{22}$

En torno a la profundización de esta línea de análisis, los resultados preliminares obtenidos con respecto del Sector de Software e Informática, permiten profundizar la idea de la presencia de ciertos "puntos luminosos" integrados a diferentes cadenas de valor y redes que operan en distintas escalas (nacional, global), con pocas vinculaciones locales que habiliten la generación de nuevos conocimientos y en las dinámicas de aprendizaje. ${ }^{23}$

Finalmente, el objetivo es el retorno a los ejes teóricos y metodológicos de análisis de los tres centros seleccionados en esta primera fase de investigación. Ello por cuanto este estudio comienza a delinear interrogantes para profundizar en una línea de trabajo sobre el funcionamiento del sistema de ciudades intermedias en el país, y en la definición de políticas públicas orientadas a su fortalecimiento.

\section{Consideraciones finales: retomando una agenda de investigación}

Una agenda de investigación sobre este tipo de centros urbanos no debería dejar afuera los orígenes de las diferentes trayectorias que se observan en los territorios. Sin duda, este eje que surge del estudio de los tres casos revela la importancia de la recuperación de la trayectoria urbano-regional, en el marco de las dinámicas nacionales e internacionales. En otros términos, los hitos históricos relacionados con los grandes ciclos de la economía argentina y su impronta sobre las estructuras económicas y sociales urbanas y, más en general, los rasgos que tipifican los procesos de acumulación a escala local regional.

Geo UERJ - Ano 15, no . 24, v. 1, $1^{\circ}$ semestre de 2013 p. 339-370

ISSN: 1415-7543 E-ISSN: 1981-9021

http://www.e-publicacoes.uerj.br/index.php/geouerj 
Conectado a lo anterior, la importancia de capturar analíticamente el conjunto de transformaciones estructurales que se vienen dando en las actividades intensivas en recursos naturales. Ello refleja, de algún modo, las derivaciones que se manifiestan en las bases económicas urbanas, los mercados de trabajo y, entre otros síntomas importantes, la intensidad y signo del ciclo económico en el mediano y largo plazo.

Queda claro, en estos casos, que la expansión económica reciente poco ha modificado los aparatos productivos en términos de diversificación (relacionada y no relacionada). El mercado laboral, a pesar de la tendencia ascendente, no muestra grandes cambios en su estructura; y son pobres los resultados en términos del peso cuantitativo que detentan las actividades de alto y medio contenido tecnológico. Lo que sí modifica el rumbo en el caso de Neuquén, son las transformaciones introducidas en el circuito de los hidrocarburos a partir de la reciente renacionalización de la empresa YPF (Yacimientos Petrolíferos Fiscales), la prioridad otorgada al autoabastecimiento y la regulación del mercado de hidrocarburos, que redefine las relaciones interempresarias, y entre las jurisdicciones del Estado, en materia de distribución accionaria, propiedad de los recursos del subsuelo, planificación sectorial, desarrollo tecnológico, otorgamiento de concesiones, inversiones de exploración, producción, industrialización y transporte, distribución de regalías, etc.

Por último, un aspecto que abre otro conjunto de interrogantes es el que refiere al peso de las estructuras públicas de innovación y de las dinámicas de asociación y vinculación tecnológica en la construcción de entornos innovadores y en la emergencia de ventajas locacionales en las ciudades intermedias, sumado ello a las inversiones en infraestructura de conectividad. En este marco, los aportes teóricos rescatados a partir de la conceptualización del path dependence pueden ser un buen punto de partida para la elaboración de taxonomías que permitan evaluar las posibilidades de cambios y complejización de las estructuras productivas urbano-regionales.

\section{Bibliografía:}

AYDALOT, Philippe. Milieux Innovaturs en Europe. Colloque Gremi, Paris. 1986.

AYDALOT, Philippe y David KEEBLE. High technology industry and innovative environments. Croom Helm, Londres. 1992.

ASIÁN CHAVES, Rosario. La globalización de los servicios en la economía andaluza: el caso de los servicios avanzados a las empresas. Tesis Doctoral, Universidad de Sevilla. 2002a

Geo UERJ - Ano 15, nº 24, v. 1, $1^{\circ}$ semestre de 2013 p. 339-370

ISSN: 1415-7543 E-ISSN: 1981-9021

http://www.e-publicacoes.uerj.br/index.php/geouerj 
ASIÁN CHAVES, Rosario. ¿Tercerización de la economía andaluza?: la estructura productiva andaluza y los servicios en la globalización. En Revista Estudios Regionales, 58, 2002b. pp. 79111.

BOLAY, Jean-Claude y Adriana RABINOVICH. Ciudades intermedias: ¿una nueva oportunidad para un desarrollo regional coherente en América Latina?. En DILLA, Haroldo (coord.). Globalización e Intermediación Urbana en América Latina. Flacso. Santo Domingo. 2004. Disponible en http://nccrns.epfl.ch/public_pdf/Ciudades_Intermedias_Bolay_Rabinovich.pdf BORELLO, José; Hernán MORHORLANG y Diego SILVA FAILDE. Economía de Aglomeración en las industrias automotriz y siderúrgica en Buenos Aires. En Desarrollo Económico, 195 (49). 2009. p. 479-509.

BRANDÃO, Carlos. Territorios \& Desenvolvimento: as múltiplas escalas entre o local e o global. Editora UNICAMP. Campinas. 2007

CAMAGNI, Roberto. Empirical identification of innovative milieux in European lagging regions. Colloque GREMI. Paris. 1992

CAMAGNI, Roberto. Economía Urbana. Antoni Bosch, Barcelona. 2005

CASTRO, Hortensia y Carlos REBORATTI. Revisión del concepto de ruralidad en la Argentina y alternativas posibles para su redefinición (PROINDER, Serie de Estudios e Investigaciones $\mathrm{N}^{\circ}$ 15), PROINDER, Buenos Aires. 2008.

DAVID, Paul. Path dependence: a foundational concept for historical social science. Cliometrica, 2 (1), 2007. p. 91-114. Disponible en: http://wwwsiepr.stanford.edu/workp/swp06005.pdf40

DE MATTOS, Carlos. Ciudades intermedias y desconcentración territorial: propósitos, alcances y viabilidad. [versión electrónica], Revista Eure, 11 (32), 1984. p. 7-34.

DÍNIZ, Clelio Campolina; Fabiana SANTOS y Marco CROCCO. Conhecimento, innovacao e desenvolvimento regional/local. En Clelio Campolina DINIZ y Marco CROCCO. Economía regional y urbana: contribucioes teóricas recentes. Editorial da UFMG, Belo Horizonte. 2006

DOSI, Giovani y Richard NELSON. An introduction to evolutionary theories in economics. En Journal of Evolutionary Economics, 3 (4), 1994. p. 327-346.

FERNANDES, Ana Cristina; Jan BITOUN y Tania Bacelar de ARÁUJO. Tipologia das cidades brasileiras. Letra Capital y Observatório das Metrópoles, Rio de Janeiro. (2009)

GARRETT, James. Beyond rural urban: keeping up with Changing Realities. IFPRI Issue Brief, 37. 2005

GLAESER, Edward; Hedi KALLAL; José SCHEINKMAN y Andrei SHLEIFER. Growth in cities. En Journal of Political Economy, 100, 1992. p. 1126-1152.

Geo UERJ - Ano 15, nº 24, v. 1, $1^{\circ}$ semestre de 2013 p. 339-370

ISSN: 1415-7543 E-ISSN: 1981-9021

http://www.e-publicacoes.uerj.br/index.php/geouerj 
GORENSTEIN, Silvia; Mariana OLEA, Carolina PASCIARONI y Guillermina URRIZA. Tópicos del debate contemporáneo sobre ruralidad e intermediación urbana: aportes para el análisis en Argentina. En RAINER, Randolph y Barbra SOUTHERN (org.). Expansão metropolitana e transformações das interfaces entre cidade, campo e região na América Latina. Editora Max Limonad, São Paulo. 2010

GORENSTEIN, Silvia. Acumulación y desarrollo regional: discusiones, enfoques y temas sobre la experiencia del Norte argentino. En Silvia GORENSTEIN (org.). ¿Crecimiento o desarrollo?: el ciclo reciente en el norte argentino. Miño y Dávila. Buenos Aires. 2012

GORENSTEIN, Silvia; LANDRISCINI, Graciela, HERNÁNDEZ Jorge (comps). Economía urbana y ciudades intermedias. Trayectorias pampeanas y norpatagónicas. Ediciones CICCUS. Buenos Aires. 2012.

GUTMAN, Graciela y Silvia GORENSTEIN. Territorio y Sistemas Agroalimentarios: enfoques conceptuales, dinámicas recientes en Argentina. En Desarrollo Económico, 168 (42), 2003, p. 563-588.

HENDERSON, Vernon. Medium Size Cities. En Regional Science and Urban Economics, 6 (27), 1997, p. 583-612.

HILDRETH, Paul. Roles and Economic Potential of English MediumSized Cities: a discussion paper. En University of Salford, Salford, 2006. Disponible en: www.surf.salford.ac.uk41

HODGSON, Geoffrey. A Modern Reader in Institutional and Evolutionary Economics. Edward Elgar Publishing, Chentelham. 2002

JOUVAUD, Magalí. Localisation des services aux entreprises: combinasion de facteurs et types d' activités. En Notes der recherche du centre de' economie regionale d' Alix-en-Provence, $\mathrm{N}^{\circ}$ 173. 1995

INNOBASQUE. Aproximación al sector de servicios avanzados. Borrador de Trabajo. 2009.

ISARD, Walter. Métodos de análisis regional: una introducción a la ciencia regional, Editorial Ariel, Barcelona. (1973),

JACOBS, Jane. La economía de las ciudades. Ediciones Península, Barcelona. 1971

KAY, Cristobal. Algunas reflexiones sobre los estudios rurales en América Latina. En Revista Ícono, 29, 2007. p. 31-50.

KRUGMAN, Paul. Increasing returns and economic geography. En Journal of Political Economy, 99, 1991. p. 483- 499.

KRUGMAN, Paul y Raúl LIVAS ELIZANDO. Trade policy and the Third World metropolis. En Journal of Development Economics, 49, 1996. p 137-150.

Geo UERJ - Ano 15, nº. 24, v. 1, $1^{\circ}$ semestre de 2013 p. 339-370 ISSN: 1415-7543 E-ISSN: 1981-9021 http://www.e-publicacoes.uerj.br/index.php/geouerj 
LANDRISCINI, Graciela y Griselda DOMEETT. El escenario postconvertibilidad y las evidencias en la estructura empresaria neuquina. Cuaderno de Investigación $\mathrm{N}^{\mathrm{o}} 2$. Facultad de Economía y Administración. Universidad Nacional del Comahue. Neuquén, 2004. p. 1-24.

LLOP TORNÉ, Josep. Ciudades intermedias y urbanización mundial. Programa UIA-CIMES, UNESCO, UIA, Ajuntament de Lleida, Lleida. 1999

LLOP TORNÉ, Josep. Megalópolis, metrópolis y ciudades intermedias del mundo. Programa UIA-CIMES, Documento 5, 2000. Disponible en http://www.paeria. es/cimes/cas/indexe.htm MACKINNON, Danny; Andrew CUMBERS; Andy PIKE; Kean BIRCH y Robert MCMASTER. Evolution in economic geography: institutions, political economy and adaptation. En Economic Geography, 2 (85), 2009. p 129-150.

MAILLAT, Denis y Jean Claude. PERRIN (edits.) Enterprises innovatrices et development territorial. GREMI-EDES, Neuchatel. 1992

MAILLAT, Denis; Michel QUÉVIT y Lanfranco SENN (edits.) Réseaux de innovation; el milieux innovateurs: un pari pour it developpment regional. GREMI-EDES, Neuchatel. 1993.

MANZANAL, Mabel. Regiones, territorios e institucionalidad del Desarrollo Rural. En Mabel MANZANAL; Guillermo NEIMAN y Mario LATTUADA (compiladores). Desarrollo Rural: organizaciones, instituciones y territórios. Ciccus, Buenos Aires. 2006

MARQUES DA COSTA, Eduarda. Cidades Médias: contributos para a sua definição. Em Revista Portuguesa de Geografia Finisterra, 74 (27), 2002. p 101-128.

MÁRQUEZ LÓPEZ, Lisett y Emilio PRADILLA COBOS. Desindustrialización, terciarización y estructura metropolitana: un debate conceptual necesario. En Cuadernos del CENDES, 69 (25), 2008. p 21-45.

MARSHALL, Alfred. Principles of economics: an introductory volume. ( $8^{\mathrm{a}}$ ed.) MacMillan, Londres. 1972

MARTIN Ron y Peter SUNLEY. Path dependence and regional economic evolution. En Papers in evolutionary economic geography, 06.06, 2006. 49 p.

MARTIN Ron y Peter SUNLEY. The place of path dependence in an evolutionary perspective on the economic landscape. En Ron BOSCHMA y Ron MARTIN (eds.), The Handbook of Evolutionary Economic Geography, Edward Elgar, Cheltenham. 2010

MÉNDEZ, Ricardo. Geografía económica: la lógica espacial del capitalismo global. Editorial Ariel, Barcelona. 1997

MÉNDEZ, Ricardo. Innovación tecnológica y reorganización del espacio industrial: una propuesta metodológica. En Revista EURE, 73 (24), 1998. p 31-54.

MÉNDEZ, Ricardo e Inmaculada CARAVACA. Organización industrial y territorio. Ed. Síntesis, Madrid. 1999

Geo UERJ - Ano 15, nº. 24, v. 1, $1^{\circ}$ semestre de 2013 p. 339-370

ISSN: 1415-7543 E-ISSN: 1981-9021

http://www.e-publicacoes.uerj.br/index.php/geouerj 
MILES, Ian, Nikos KASTRINOS, Rob BILDERBEEK, Pim DEN HERTOG, Kieron FLANAGAN, Willem HUNTINK y Mark BOUMAN. Knowledge-intensive business services: users, carriers and sources of innovation. PREST, Manchester. 1995

MOULAERT, Frank y Abid MEHMOOD. Analysing regional development: from territorial innovation to path dependent geography. En John DAVIS y Wilfred DOLFSMA (eds.). The Elgar Companion to Social Economics. Edward Elgar, Cheltenham. 2008. p. 607-631

MUÑIZ OLIVERA, Iván. Externalidades y cambio técnico endógeno: un repaso a la literatura sobre crecimiento regional y local. Documento de trabajo del Departament d'Economia Aplicada de la Universitat Autónoma de Barcelona N 98.03. , Barcelona, marzo 1998

OLEA, Mariana. Ruralidad, Educación y Desarrollo Territorial: una mirada desde las instituciones educativas del Sudoeste Bonaerense. Tesis para optar al grado de Magíster en Desarrollo y Gestión Territorial, Universidad Nacional del Sur, Bahía Blanca, Argentina. 2011 OLIVEIRA, Gilverto. Redefinição da centralidade urbana em cidades médias. Em Sociedade \& Natureza, Uberlândia, 20 (1), 2008. p 205-220.

PÓLESE, Mario y Fernando RUBIERA MOROLLÓN. Economía urbana y regional: introducción a la geografía económica. Biblioteca Civitas de Economía y Empresa, Colección Economía, Thomson Reuters, Ed. Aranzadi, Pamplona. 2009

PRADILLA COBOS. Emilio Contribución a la crítica de la teoría urbana: del espacio a la crisis urbana. Universidad Autónoma Metropolitana. Xochimilco. 1984

PRECEDO LEDO, Andrés. La ciudad en el territorio: nuevas redes, nuevas realidades. En Lorenzo LÓPEZ TRIGAL, Carlos RELEA FERNÁNDEZ y José SOMOZA MEDINA (coords.). La ciudad, nuevos procesos, nuevas respuestas: coloquio de Geografía urbana. Biblioteca Virtual Miguel de Cervantes, Alicante, 2002. Disponible en http://descargas.cervantesvirtual.com/servlet/SirveObras/013

PULIDO, Norma. Globalización y surgimiento de ciudades 'intermedias' en América Latina y en Venezuela. En Revista Geográfica Venezolana, 45 (1), 2004. p 91-121.

SANTOS, Milton. De la totalidad al lugar. Oikos-Tau, Barcelona. 1996

SASSEN, Saskia. Ciudades en la economía global: enfoques teóricos y metodológicos. En Revista EURE, 71 (24), 1998. p 5-25.

SASSEN, Saskia. La ciudad global: Nueva York, Londres, Tokio. Eudeba, Buenos Aires. 1999

SASSEN, Saskia. Una sociología de la globalización (2da. reimpresión), Katz discusiones, Buenos Aires. 2010

SCITOVSKY, Tibor. Two Concepts of External Economies. En Journal of Political Economy, 62, 1954. p 143-51.

Geo UERJ - Ano 15, nº 24, v. 1, $1^{\circ}$ semestre de 2013 p. 339-370

ISSN: 1415-7543 E-ISSN: 1981-9021

http://www.e-publicacoes.uerj.br/index.php/geouerj 
SCHREYOGG, Georg y Jorg SYDOW. Understanding Institutional and Organizational Path Dependencies. En Georg Schreyogg y Jor Sydow (eds.). The Hidden Dynamics Of Path Dependency. Palgrave-Macmillan, Londres. 2010

SIMMIE, James; Juliet CARPENTER; Andrew CHADWICK and Ron MARTIN. History matters: path dependence and innovation in British city-regions. Nesta, Londres. 2008

USACH, Natalia y Rubén GARRIDO YSERTE. Globalización y ciudades en América Latina: ¿es el turno de las ciudades intermedias en la Argentina?. En Documentos y aportes en administración pública y gestión estatal, 13, 2009. p. 07-38. Disponible en http://www.scielo.org.ar/scielo.php

VELTZ, Pierre. A quoi ser la proximité dans la economie. En Michel SAVY y Pierre VELTZ (dirs.). Economie globale et reinvention du local. Editions de L' Aube, Marsella. 1995

WELLER, Jurgen. El empleo terciario en América Latina: entre la modernidad y la sobrevivencia. En Revista de la CEPAL, 84, 2004. p. 159-176.

\footnotetext{
${ }^{1}$ PICT-Red 2044 "Sistemas productivos locales y ciudades intermedias. Trayectorias urbano-regionales Pampeanas y Norpatagónicas" financiado por Agencia Nacional de Promoción Científica y Tecnológica. Resultados de esta investigación, que se recogen en éste artículo, han sido publicados en Gorenstein S, Landriscini G., Hernández J. (Coord, 2012).

2 "La idea de formación y/o fortalecimiento de ciudades intermedias siempre ha estado vinculada a un intento de aproximación a esquemas ideales de asentamientos humanos. Desde los modelos espaciales de equilibrio, como aquellos que tienen su fundamento en las teorías del lugar central de Lösch y Christaller, las diversas propuestas conocidas han preconizado una distribución óptima de centros urbanos en el territorio, en el entendimiento de que ellos habrán de desempeñar un papel fundamental en los procesos reorganización territorial." (de Mattos, 1984: 24)

${ }^{3}$ Según un Informe de Naciones Unidas del año 2009, el 52\% de la población urbana del planeta vive en centros urbanos con menos de 500 mil habitantes, los que precisamente muestran mayores tasas de crecimiento poblacional en las últimas décadas (Usach y Garrido Yserte, 2009: 3).

${ }^{4}$ Diversos autores concuerdan en que las ciudades intermedias poseen ciertas ventajas competitivas con relación a las de mayor escala, entre las cuales cabe mencionar la conectividad, los menores niveles de contaminación ambiental, menores costos y mayor calidad de vida, la reducción de los tiempos de desplazamiento diarios, el sentimiento de identidad y los mayores niveles de seguridad; como también una masa crítica institucional y empresarial relativamente más elevada que el resto de los centros urbanos en cada contexto regional, y una dotación diferencial de recursos técnicos, económicos y financieros entre las más destacadas. (Olivera, 2008; Llop Torné, 1999, entre otros).

${ }^{5}$ Hildreth (2006) clasifica las ciudades intermedias en: ciudad industrial, ciudad acceso o gateway city, ciudad patrimonial o turística, ciudad universitaria, ciudad localizada en la región urbana de una gran ciudad, ciudad capital, y ciudad de servicios regionales. Y Bolay y Rabinovich (2004) identifican once grandes tipos formales de intermediación: mercado regional, centro de servicios, capital regional, localidad económica, centro turístico, centro de comunicaciones, periferia metropolitana, intercambio nacional e internacional, ciudades en un área conurbana, asociación de un grupo de pueblos y región urbana.

${ }^{6}$ El desplazamiento de la función agroproductiva a favor de funciones como la residencial o como espacio de ocio ha sido muy importante en las regiones rurales europeas. En cambio, en gran parte de las regiones rurales latinoamericanas la distancia entre el campo y la ciudad es mayor, tanto en términos reales como por la carencia de infraestructuras de comunicación, y la función agraria sigue teniendo un peso determinante, mientras que la difusión de nuevas funcionalidades se está produciendo en los hinterlands de las ciudades y centros turísticos

${ }^{7}$ A partir del trabajo de Glaeser et al. (1992), diversos autores enfatizan en la relación de la difusión tecnológica sobre el crecimiento de las ciudades y regiones, proponiendo una tipología de externalidades

Geo UERJ - Ano 15, nº. 24, v. 1, $1^{\circ}$ semestre de 2013 p. 339-370

ISSN: 1415-7543 E-ISSN: 1981-9021

http://www.e-publicacoes.uerj.br/index.php/geouerj
} 
dinámicas que distingue entre: (i) externalidades tipo MAR (Marshall, Arrow, Romer), externalidades intraindustriales en contextos oligopólicos; (ii) externalidades tipo Porter o intraindustriales con mercados competitivos; y (iii) externalidades tipo Jacobs o interindustriales, también con mercados competitivos.

${ }^{8}$ Al respecto, Santos señala que, las condiciones actuales de una economía internacional "mundializada" han hecho surgir un sinnúmero de actividades que escapan a la clasificación tradicional, ampliando cualitativa y cuantitativamente las demandas de las familias y de las empresas, sumado a las que surgen de las nuevas formas de actividad política y administrativa, tanto en la esfera pública como privada (Santos, 1996: 31).

${ }^{9}$ Para un análisis de estos aspectos, véase, entre otros: Aydalot, 1986; Aydalot et al., 1992; Camagni, 1992; Maillat et al., 1992; Maillat et al., 1993; Méndez, 1998; Diniz C., 2006; Polése y Rubiera Morollón, 2009.

${ }^{10}$ Definir los SAE reviste particular complejidad. La intensidad del conocimiento requerido para que un servicio sea considerado como "avanzado" constituye una variable difícil de definir y de cuantificar. Una definición operativa del sector de empresas de SAE fue la expuesta por Miles et al. (1995), quienes señalan que dependen fuertemente de una base de conocimiento profesional; proveen de productos que son en sí mismos fuentes de información y conocimiento para usuarios, o utilizan su conocimiento para producir servicios que son elementos intermedios para la actividad de sus clientes de generación de conocimiento propio o de procesamiento de información; y tienen a otras empresas u organizaciones como principales clientes.

11 Sassen, 1999; Veltz, 1995; Méndez, 1997; Méndez, 1998; Méndez y Caravaca, 1999; Márquez y Pradilla, 2008, entre otros.

${ }^{12}$ En este marco cabe contemplar, a su vez, que el sector servicios opera como "refugio" para la mano de obra expulsada de los otros sectores económicos, tanto en áreas y países periféricos, como en las propias "ciudades globales“ en los momentos de crisis y reestructuración (Márquez y Pradilla, 2008:8)

${ }^{13}$ Se puede traducir como "dependencia de la trayectoria".

$14 \mathrm{Su}$ temprana asociación con la utilización de términos como accidentes históricos, locked-in (encerramiento) o la identificación con el caso del teclado QWERTY llevaron a una espuria identificación del término path dependence con el estudio de la causa de la ineficiencia de ciertos desarrollos tecnológicos.

15 "As a result, economic and social theorists are obliged to build theories that in part involve historically or geographically specific assumptions. Although all theorizing involves some general categories and elements, effective theories also involve specific and particular assumptions" (Hodgson,2002: 18)

${ }^{16}$ Para una discusión sobre esta temática véase: Brandao (2007) y Gorenstein (2012).

${ }^{17}$ Más específicamente, las economías vinculadas con el contacto cara a cara que se logra en las ciudades, atendiendo que a los costos de transmisión del conocimiento "tácito" requerido para el desarrollo de la producción siguen incrementándose con la distancia.

${ }^{18}$ Estas reflexiones se han enriquecido con los aportes realizados a lo largo de la investigación, y el comentario en las etapas finales, de integrantes de los respectivos nodos de investigación.

${ }^{19}$ Se trata de los cambios que se producen con las empresas públicas privatizadas que localizan en la ciudad sus oficinas, laboratorios, centros de logística, etc., así como algunos nuevos servicios demandados por los procesos de reestructuración productiva y empresarial que se producen en la fruticultura y el circuito de los hidrocarburos.

${ }^{20}$ Se trata de las posibilidades de diversificación en industrias y sectores relacionados con la base actual de la economía regional, a partir de sistemas de spin-off de las firmas principales o de proyección de un conjunto de empresas proveedoras de bienes o servicios a la actividad principal.

21 Tal el caso Bahía Blanca con el complejo petroquímico y de Neuquén con los hidrocarburos, respectivamente. En ellas, instituciones públicas (universidades, INTA, INTI) y redes privadas han acompañado los procesos de adaptación y aprendizaje.

${ }^{22}$ Landriscini, Graciela, Domeett, Griselda; El escensario postconvertibilidad y el tejido empresario neuquino. Cuadernos de Investigación $N^{\circ}$ 2. FAEA. Universidad Nacional del Comahue. Neuquén. Argentina, 2004.

23 Preiss, Osvaldo.; Hernández, Jorge; Pasciaroni, Carolina y Costanzo Caso, Carolina, "Ciudades intermedias, recursos naturales e innovación: estudio de nodos pampeanos y norpatagonicos en Argentina”. XII Seminario de la Red Iberoamericana de Globalización y Territorio. Universidad Federal de Mina Gerais. Brasil, 1 al 4 de octubre de 2012.

Geo UERJ - Ano 15, nº 24, v. 1, $1^{\circ}$ semestre de 2013 p. 339-370

ISSN: $1415-7543$ E-ISSN: 1981-9021

http://www.e-publicacoes.uerj.br/index.php/geouerj 
Artigo recebido para publicação em maio de 2013.

Artigo aceito para publicação em maio de 2013.

Geo UERJ - Ano 15, no . 24, v. 1, $1^{\circ}$ semestre de 2013 p. 339-370

ISSN: 1415-7543 E-ISSN: 1981-9021

http://www.e-publicacoes.uerj.br/index.php/geouerj 